\title{
PENINGKATAN KINERJA KARYAWAN CV NURUL JANNAH SUMENEP DALAM MENDUKUNG USAHA PRODUK MINUMAN TABLET EFFERVESCENT KELOR
}

\author{
Ismawati $^{1}$, R. A. Destryana ${ }^{2}$, dan A. Wibisono ${ }^{3}$
}

\begin{abstract}
ABSTRAK
CV Nurul Jannah adalah UKMKM yang terbentuk dari kelompok petani kelor dan pada tahun 2012 berubah menjadi CV. CV Nurul Jannah mengolah hasil pertanian kelor menjadi produk tepung kelor, teh kelor dan beberapa snack yag berbahan kelor. CV Nurul Jannah memiliki keinginan yang kuat untuk terus berkembang dan berinovasi dalam produk olahan kelor dalam bentuk minuman instan sebagaimana tren konsumsi masyarakat terhadap produk instan saat ini. Produk minuman instan yang akan dijadikan produk inoasi oleh CV Nurul Jannah adalah tablet effervescent kelor. Kendala yang dihadapi CV Nurul Jannah untuk membuat produk inovasi mengembangkan produk kelor menjadi produk inovasi adalah kinerja karyawan yang kurang memadai. Penyebab permasalahan kinerja adalah pemahaman karyawan akan teknologi baru masih rendah dan penguasaan teknologi pengolahan kelor juga masih kurang. Melalui kegiatan pengabdian masyarakat dilaupayakan penyelesaian permasalahan dengan cara memberikan pelatihan pengolahan dan pelatihan pengoperasian alat pembuat tablet. Dalam pelaksanaan pengabdian dilakukan pengukuran antara sebelum dan sesudah pelatihan menggunakan metode Key Performance Indicator dan ditemukan adanya peningkatan kinerja karyawan. Melalui pelatihan tim produksi CV Nurul Jannah telah mampu memproduksi tablet effervescent kelor karena telah memahami formulasi bahan, pencampuran dan pencetakan.
\end{abstract}

Kata kunci : CV Nurul Jannah, effervescent, karyawan, kelor, kinerja.

\begin{abstract}
CV Nurul Jannah is a UKMKM which was formed from the Moringa farmers group and in 2012 it was changed to CV. CV Nurul Jannah processed Moringa farming produce into Moringa flour, tea and snacks made from Moringa. CV Nurul Jannah has a strong desire to continue to develop and innovate in processed Moringa products in the form of instant drinks as the current trend of consumer consumption of instant products. Instant products that will be used as an innovation product Moringa effervescent. The obstacle faced by CV Nurul Jannah to make an innovation product to develop Moringa products into innovation products is inadequate employee performance. The cause are that employees' understanding of new technology is still low and their mastery of Moringa processing technology is also lacking. The problem solving is carried out by providing processing training and training in the operation of tablet-making devices. In the implementation of servitude, measurements were taken to find out whether or not there was an increase in performance between before and after training used the Key Performance Indicator method and found an increase in employee performance. The training results it was also found that CV Nurul Jannah's production team was able to produce Moringa effervescent and they understood formulation techniques, mixing and printing techniques.
\end{abstract}

Keywords: CV Nurul Jannah, effervescent, employee, Moringa, performance.

\footnotetext{
${ }^{1}$ Program Studi Teknologi Hasil Pertanian Fakultas Pertanian Universitas Wiraraja, ismawati@wiraraja.ac.id 2 Program Studi Teknologi Hasil Pertanian Fakultas Pertanian Universitas Wiraraja,

3 Program Studi Manajemen Fakultas Ekonomi dan Bisnis Universitas Wiraraja,
} 


\section{PENDAhUluAN}

CV Nurul Jannah termasuk salah satu UMKM yang aktif dn memiliki keinginan untuk terus berkembang. Hal itu sebagaimana dapat dilihat dari awal terbentuknya CV yang bermula dari kelompok petani kelor kemudian menjadi CV. Ditinjau dari awal terbentuknya CV Nurul Jannah maka Sumber Daya Manusia pada CV Nurul Jannah umumnya adalah masyarakat petani.

Permasalahan keterbatasan pengelolaan pada CV Nurul Jannah Sumenep yaitu khusus pada kinerja yang memang dinilai masih kurang serta kemampuan dalam pengelolaan kelor menjadi suatu produk baru masih terbatas. Permasalahan kurangnya kinerja karyawan CV Nurul Jannah ditemukan berdasarkan hasil pemaparan pimpinan CV Nurul Jannah kepada tim PKM. Demikian pula dengan permasalahan keterampilan pengolahan yang menurut pimpinan CV Nurul Jannah disebabkan oleh tingkat pendidikan karyawan yang paling tinggi adalah pada jenjang Menengah Atas dan CV Nurul Jannah hingga saat ini belum pernah memberikan pelatihan atau mengikutsertakan karyawannya dalam kegiatan pelatihan.

Kinerja karyawan dalam suatu perusahaan merupakan salah satu faktor pendorong berjalannya proses yang baik yang diharapkan oleh perusahaan. Kinerja karyawan menjadi faktor penting dalam perusahaan karena kinerja karyawan termasuk dalam suatu faktor yang dapat mempengaruhi kepuasan kerja (Hidayat, 2015). Pada umumnya perusahaan mengupayakan peningkatan kinerja melalui berbagai metode seperti pelatihan atau pembinaan, penilaian, motivasi maupun pemberian reward. Peningkatan kinerja karyawan dalam UMKM (usaha mikro kecil dan menengah) perlu diupayakan. Salah satu kelemahan dari UMKM di Indonesia untuk dapat berkembang seperti perusahaan besar lainnya adalah adanya hambatan yang pada umumnya mencakup berbagai hal yaitu keterbatasan kemampuan dalam pengelolaan usaha, keterbatasan modal, keterbatasan informasi dan peluang pasar secara nasional (Mudjiarto, 2014).

Pada saat pelaksanaan pengabdian masyarakat mitra memiliki produk minuman olahan kelor yang berupa teh kelor dalam bentuk bubuk, teh celup kelor dan kapsul kelor. Tablet effervescent kelor merupakan produk invoasi kelor dalam bentuk sediaan tablet. Kelebihan tablet effervescent kelor adalah tepat takaran, mudah dalam penyajian serta praktis karena tidak perlu penambahan gula (Romantika et al, 2017). Agar dapat dihasilkan tablet effervescent yang bermutu maka harus tepat takaran dalam setiap formulasi bahan yang digunakan. Oleh sebab itu maka dalam peningkatan kinerja karyawan CV Nurul Jannah dilakukan pelatihan pengolahan mulai dari pencapuran hingga pencetakan pada mesin pentablet.

Kinerja karyawan CV Nurul Jannah dilihat berdasarkan 4 aspekang diantaranya adalah semangat bekerja, efektifitas menyelesaikan pekerjaan, kemampuan beradaptasi terhadap pekerjaan atau kemampuan mengadopsi metode baru dalam pelaksanaan pekerjaan dan kualitas bekerja. Berdasarkan pemaparan pimpinan CV Nurul Jannah keempat aspek harus selalu tertanam pada karyawan CV Nurul Jannah terlebih lagi dalam mendukung usaha produk baru yaitu tablet effervescent.

Berdasarkan dua permasalahan yang dihadapi CV Nurul Jannah dalam kinerja karyawan maka tim PKM mengupayakan peningkatan kinerja karyawan CV Nurul Jannah Sumenep melalui pelatihan. Pelatihan termasuk salah satu kegiatan yang dapat dijadikan upaya untuk meningkatkan kualitas kerjaa, produktivitas kerja, meningkatkan ketetapan perencanaan Sumber Daya Manuasia, meningkatkan sikap moaral dan semangat kerja, meningkatkan prestasi karyawan, mengurangi keusangan serta mendukung perkembangan kemampuan karyawan dalam perusahaan (Wijaya, 2013). Makalah ini ditulis sebagai bentuk dokumentasi alam kegiatan pengabdian masyarakat dan diharapkan dapat dijadikan acuan dalam pelaksanaan kegiatan yang sama sebagai upaya meningkatkan kinerja pendampingan masyarakat. 


\section{METODE PELAKSANAAN}

Pelaksanaan pengabdian masyarakat terdiri dari 2 kegiatan yaitu kegiatan pelatihan dan evaluasi. Tim pengabdian bertugas dalam memberikn pelatihan dan mengevaluasi sementara tim mmitra yaitu karyawwan CV Nurul Jannah merupakan peserta pelatihan. Kegiatan pelatihan diikuti oleh semua karyawan CV Nurul Jannah yang berjumlah 18 orang. Kegiatan pelatihan dilaksanakan di lokasi CV Nurul Jannah yang beralamat di Desa Pakandangan Sangra Kecamatan Bluto Kabupaten Sumenep Madura.

Agar dapat diketahui ada atau tidaknya peningkatan kinerja karyawan maka dilakukan pengukuran kinerja sebelum diberikan pelatihan oleh tim PKM. Pengukuran kinerja awal diperlukan untuk menentukan indikator pencapaian dalam pelatihan yang diberikan kepaa kryawan CV Nurul Jannah. Peningkatan kinerja diukur dengan metode Key Performance Indicator. Key Performance Indicator merupakan alat bantu manajemen dalam perusahaan untuk membandingkan antara rencana dan capain perencanaan. KPI dibuat oleh perusahaan sebagai target selanjutnya masing-masing target di berikan bobot untuk mempermudah proses pencapaian (Lubis \& Kusumanto, 2018; Rokhim, 2017).

Untuk dapat meningkatkan semangat kerja, efektifitas penyelesaian pekerjaan, kemampaun adaptasi dan meningkatkan mutu kualitas pekerjaan maka diberikan pelatihan melalui penyajian materi manajemen oleh tim PKM yang memiliki keahlian dalam ilmu manajemen. Selanjutnya pelatihan pengolahan tablet effervescent diberikan oleh tim PKM yang memiliki keahlian dalam teknologi pengolahan.

Materi pelatihan disajikan dalam bentuk power point template dengan menyertakan gambar agar penyampaian materi mudah dimengerti dan tidak membosankan peserta pelatihan. Peseta pelatihan juga diberikan modul pengolahan tablet effervescent kelor yang berisi materi tentang manfaat kelor, tablet effervescent kelor, serta cara pengolahan tablet effervescent kelor.

Dalam pelatihan juga diperagakan cara pencampuran bahan dalam pembuatan tablet effervescent kelor. Selain itu juga diberikan penjelasan tentang komponen mesin pentablet, cara penggunaan mesin pentablet serta cara perawatan mesin pencetak tablet otomatis. Semua pelatihan yang diberikan tentu bertujuan untuk meningkatkan kinerja karyawan CV Nurul Jannah dalam mendukung usaha produk baru yang berupa minuman instan kelor dalam bentuk sediaan tablet effervescent.

\section{HASIL DAN PEMBAHASAN}

Kegiatan pelatihan yang dilaksanakan berjalan dengan baik dimana peserta pelatihan adalah seluruh karyawan CV Nurul Jannah Sumenep sebagaimana yang telah direncanakan. Masing-masing pelatihan dilakukan selama kurang lebih 4 jam di CV Nurul Jannah. Untuk evaluasi hasil kegiatan dilakukan pengumpulan data dengan menyebarkan kuesioner pada karyawan CV Nurul Jannah. Data yang didapatkan melalui pemberian kuesioner selanjutnya dianalisis untuk mengetahui ada tidaknya penningkatan kinerja sesuai yang ditargetkan dalam pelaksanaan pengabdian masyarakat.

Dalam pelaksanaan pengambilan data kuesioner, tim PKM memberikan kuesioner kepada pimpinan CV Nurul Jannah untuk selanjutnya diisi oleh karyawan. Evaluasi dalam pengabdian bertujuan untuk meninjau kembali kegiatan yang telah dilakukan dan kemudian dapat menjadi koreksi apabila ada kesalahan. Kegiatan evaluasi juga dapat dilakukan untuk mengetahui kepuasan mitra terhadap pelaksanaan kegiatan yang telah dilaksanakan bersama mitra sebagaimana yang dilakukan dalam pendampingan oleh VH dan Susilowati dalam kegiatan pemberdayaan ibu-ibu PKK untuk dapat memproduksi sabun dan deterjen secara mandiri (VH \& Susilowati, 2016).

\subsection{Pelaksanaan Pelatihan}

Pelatihan dilakukan 2 tahap yaitu pelatihan manajemen usaha dan pelatihan pengolahan tablet. Penyampaian materi dan praktik untuk masing-masing pelatihan manajemen dan pengolahan dilaksanakan pada waktu dan hari yang berbeda agar peserta tidak merasa jenuh karena masing-masing pelatihan dialokasikan selama 4 jam. Dalam pelatihan manajemen usaha, peserta diberikan kesempatan untuk bertanya dan berdiskusi yang terkait dengan permasalahan kerja yang dihadapi oleh masing-masing karyawan CV Nurul Jannah. Pelatihan manajemen usaha diikuti oleh seluruh karyawan CV Nurul Jannah yang berjumlah 18 orang berserta satu 
orang pemilik CV Nurul Jannah. Dokumentasi pelatihan manajemen usaha sebagaimana disajikan pada Gambar 1.

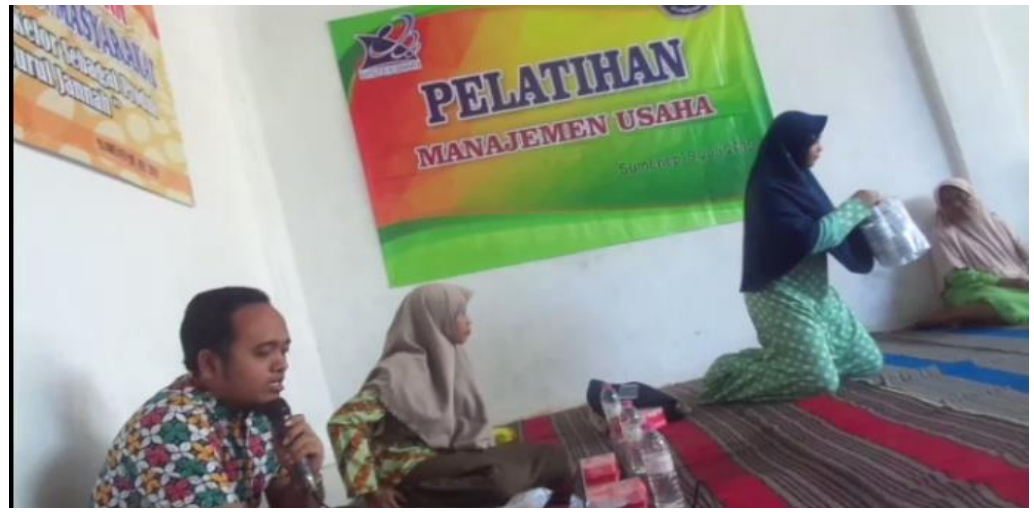

Gambar 1. Pelatihan Manajemen Usaha

Pelatihan pengolahan minuman instan tablet effervescent kelor diikuti oleh bagian produksi CV Nurul Jannah beserta pemilik CV Nurul Jannah. Materi yang disampaikan dalam pelatihan pembuatan tablet effervescent adalah formulasi yang digunakan, pencampuran bahan dan pencetakan tablet effervescent kelor. Pada pelatihan pengolahan tablet effervescent kelor, peserta diberikan kesempatan untuk mencoba mencampur bahan pentablet serta mencetak bahan yang telah tercampur secara homogen. Dokumentasi pelaksanaan kegiatan pelatihan pengolahan tablet effervescent kelor sebagaimana pada Gambar 2. Pada Gambar 3 disajikan tablet effervescent kelor dari hasil pelatihan.

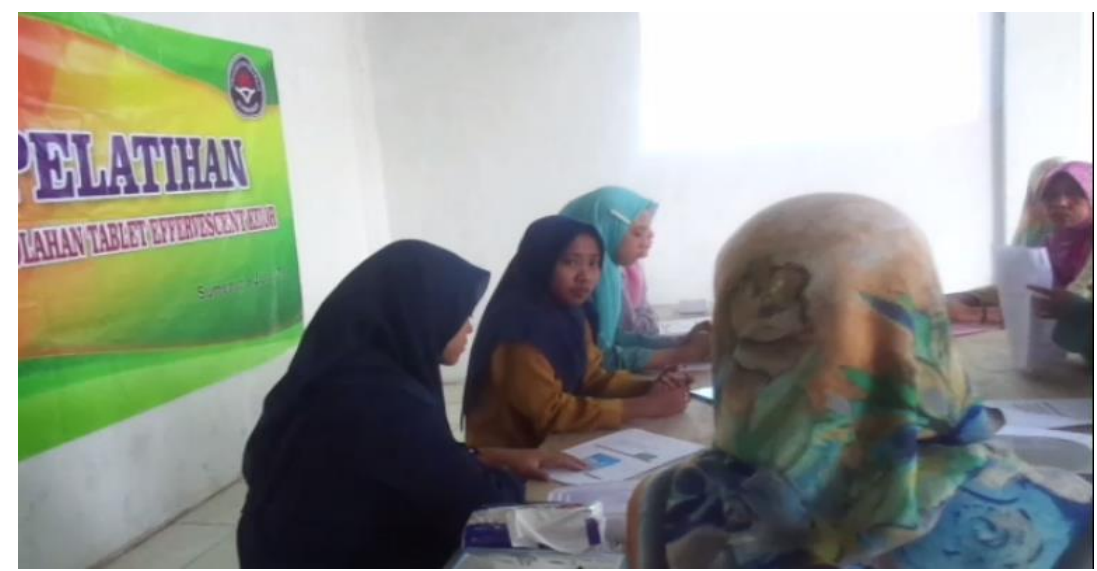

Gambar 2. Pelatihan Pengolahan Tablet Effeverscent Kelor

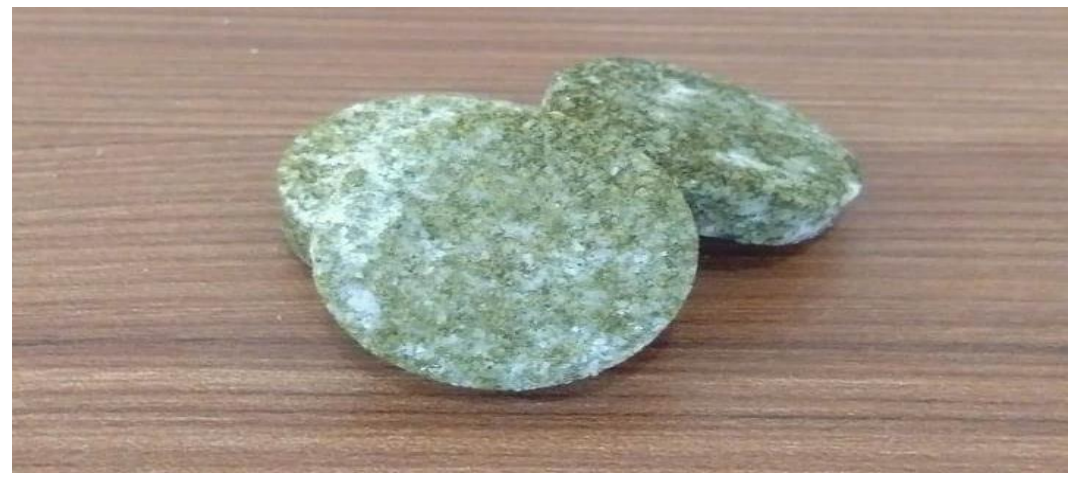

Gambar 3. Minuman Tablet Effervescent yang Dihasilkan Peserta pelatihan 
Faktor dalam pembuatan tablet effervescent kelor adalah ketepatan formulasi bahan yang digunakan. Konsentrasi bahan pemanis (stevia) dalam pembuatan tablet effervescent dapat mempengaruhi kesukaan konsumen sebagaimana penelitian yang telah dilakukan oleh dalam pembuatan tablet effervescent temu lawak (Paramita et al., 2015). Dalam formulasi tablet effervescent kelor pemanis yang digunakan adalah sorbitol. Penggunaan sorbitol sebagai pemanis karena produk miuman kelor dalm sediaan tablet dikhususkan untuk menjadi produk yang fungsional termasuk didalamnya rendah gula.

Pada kegiatan pengabdian masyarakat juga didesain alat pentablet otomatis untuk mendukung kegiatan produksi tablet effervescent kelor. Desain dan perancangan alat pentablet otomatis tentu juga bertujuan untuk mempermudah pelaksanaan produksi khususnya bagi karyawan bidang produksi. Tim pengabdain juga memberikann penjelasan tentang cara pengoperasian alat pentablet otomatis. Dokumentasi penjelasan komponen alat pentablet disajikan pada Gambar 4.

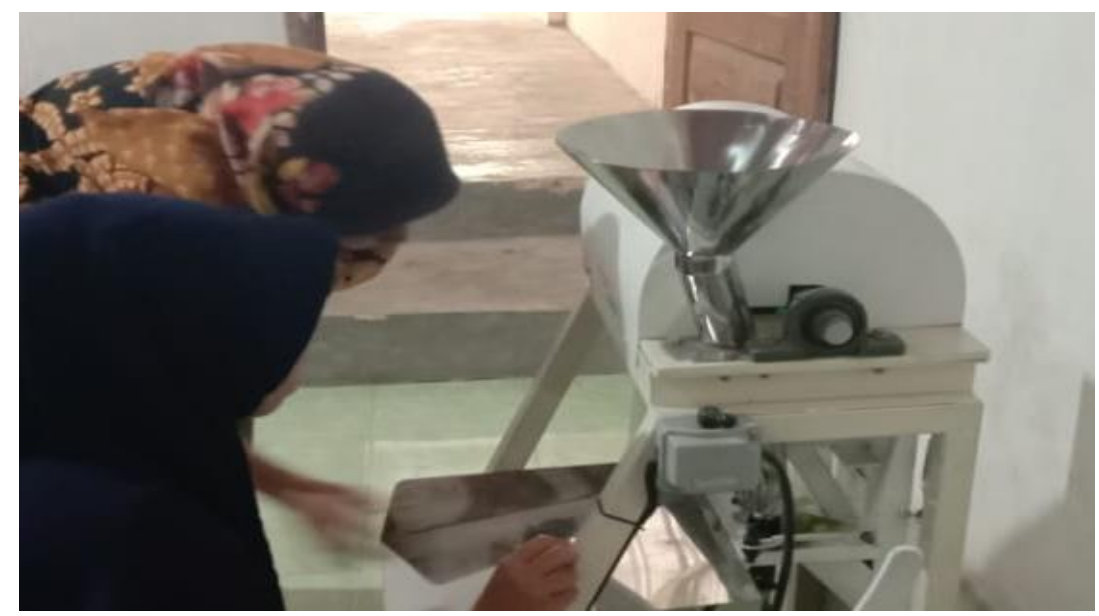

Gambar 4. Penjelasan Komponen Alat Pentablet

\subsection{Evaluasi}

Pelaksanaan kegiatan pelatihan ditujukan untuk meningkatkan kinerja karyawan pada CV Nurul Jannah. Metode yang dapat dilakukan dalam perusahaan untuk pengembangan karyawan dalam mencapai efektifitas kerja diantaranya pelatihan, understudy, job rotasi dan coaching-counseling (Wijaya, 2013). Kegiatan pelatihan yang diberikan oleh tim PKM kepada tim mitra perlu diukur tingkat ketercapaiannya dengan dilakukan evaluasi. Dalam proses evaluasi kinerja, untuk dapat dilakukan pengukuran kinerja dilakukan pengambilan data kinerja karyawan dengan cara memberikan kuesioner kepada seluruh karyawan CV Nurul Jannah. Pengambilan data dilakukan sebelum dan sesudah pelatihan.

Kuesioner sebelum pelatihan diberikan pada Bulan Juni 2019 sementara pelatihan dilaksanakan pada Bulan Juli 2019 dan pengisian kuesioner setelah pelatihan dilakukan pada Bulan Agustus 2019. Kegiatan pelatihan memberikan dampak terhadap peingkatan kinerja karyawan CV Nurul Jannah berdasarkan indikator capaian terhadap semangat kerja, efektifitas penyelesaian pekerjaan, peningkatan kemampuan adaptasi terhadap metode baru serta peningkatan kualitas kerja karyawan.

Indikator dalam pengukuran kinerja karyawan adalah dengan menggunakan skala pengukuran dari angka 1-5. Skala 1 menunjukkan sangat kurang baik, skala 2 menunjukkan kurang baik, skala 3 : artinya cukup, skala 4 menunjukkan baik dan skala 5 menunjukkan sangat baik. Adapun hasil analisis peningkatan kinerja karyawan CV Nurul Jannah sebelum dan sesudah dilaksanakan pelatihan sebagaimana disajikan pada Tabel 1. 
Tabel 1. Hasil Pengukuran Kinerj Karyawan CV Nurul Jannah

\begin{tabular}{|l|c|c|c|c|c|}
\hline \multicolumn{1}{|c|}{ Kinerja Sebelum dan Sesudah } & \multicolumn{3}{c|}{ Indikator Pencapaian Kinerja } \\
\cline { 2 - 7 } & $\mathbf{1}$ & $\mathbf{2}$ & $\mathbf{3}$ & $\mathbf{4}$ & $\mathbf{5}$ \\
\hline Nilai Kinerja sebelum & 16 & 28 & 51 & 47 & 29 \\
\hline Nili Kinerja setelah & 3 & 8 & 49 & 62 & 49 \\
\hline Prosentase naik/turun & $-81 \%$ & $-71 \%$ & $-4 \%$ & $32 \%$ & $69 \%$ \\
\hline
\end{tabular}

Berdasarkan data pada Tabel 1, setelah dilakukan pelatihan, maka pencapaian kinerja karyawan CV Nurul Jannah mengalami peningkatan yaitu penilaiannya mayoritas sudah mencapai skala 5 . Dengan peningkatan prosentase seperti pada tabel 1. Dimana skala 1 sampai 3 sudah menurun sedangkan pada skala 4 dan 5 mengalami peningkatan. Sehingga dapat diambil kesimpulan, bahwa kinerja karyawan sudah mengalami peningkatan.

\section{UCAPAN TERIMA KASIH}

Kami sampaikan terima kasih kepada Direktorat Riset dan Pengabdian Masyarakat, Direktorat Jenderal Penguatan Riset dan Pengembangan Kementerian Riset, Teknologi, dan Pendidikan Tinggi Republik Indonesia yang mendanai pelaksanaan Kegiatan Pengabdian Kepada Masyarakat Tahun 2019.

\section{DAFTAR PUSTAKA}

Hidayat, R. (2015). Performance Appraisal sebagai Alat Pengukuran Kepuasan Kerja Karayawan. Ilman, $3(1), 1-8$.

Lubis, P. I., \& Kusumanto, I. (2018). Penilaian Kinerja Karyawan Menggunakan Metode Key Performance Indicators ( KPI ) ( Studi Kasus: Cv . Bunda Bakery Pekanbaru ) CV . Bunda Bakery is a long established cake manufacturer . The process of making cakes in. Jurnal Sains, Teknologi Dan Industri, $15(2), 37-45$.

Mudjiarto, M. (2014). Pengaruh Pembinaan Manajemen Usaha Terhadap Kinerja Usaha Mitra Binaan PKBL PT Jasa Marga. Jurnal Ekonomi Universitas Esa Unggul, 5(2), 1-8.

Paramita, I. I., Mulyani, S., \& Hartiati, A. (2015). Pengruh Konsentrasi Maltodekstin dan Suhu Pengeringan Terhadap Karakteristik Bubuk Minuman Sinom. Rekayasa Dan Manajemen Agroindustri, 3(2), 58-68.

Rokhim, M. (2017). Penentuan Key Performance Indicator Dengan Metode Balanced Scorecard. Jurnal Teknik Industri, 18(02), 168-175. Retrieved from https://doi.org/10.22219/JTIUMM

Romantika, R. C., Wijana, S., \& Perdani, C. G. (2017). Formulasi dan Karakteristik Tablet Effervescent Jeruk Baby Java ( Cytrus sinensis L . Osbeck ) Kajian Proporsi Asam Sitrat Effervescent Tablets Study on Cytric Acid Proportion. Industria: Jurnal Teknologi Dan Manajemen Agroindustri, 6(1), 15-21.

VH, E. S., \& Susilowati, E. (2016). Pemberdayaan Ibu-Ibu PKK Melalui Pelatihan dan Pendampingan Produksi sabun dan Deterjen. Jurnal Ilmu Pengetahuan, Teknologi, Dan Seni Bagi Masyarakat, 4(2), 87-96.

Wijaya, W. (2013). Analisis Pelatihan dan Pengembangan Sumber Daya Manusia Pada Pabrik Kecap Wie Sin Di Lombok. Jurnal AGORA, l(3). 